\title{
The Motivation of Tourism Photography Online Sharing
}

\author{
Xuemin Zhang ${ }^{1, a,{ }^{*},}$ Xiaoyi $\mathrm{Wu}^{2, \mathrm{~b}}$, Xue Yan ${ }^{3, \mathrm{c}}$ \\ 1,2,3School of Management, Xiamen University, Xiamen, China \\ a1754099633@qq.com, bwxy501@xmu.edu.cn, cst7vyen@qq.com \\ ${ }^{*}$ Corresponding author
}

\begin{abstract}
Keywords: Tourism photography, online sharing, extrinsic motivation, intrinsic motivation.
\end{abstract}
\begin{abstract}
The online sharing of tourism photography has been a widespread phenomenon in recent years. However, few studies empirically analyzed the motivation of why tourists share photos online. From the perspective of aesthetic experience theory and self-determination theory, two extrinsic motivations (i.e. destination attractiveness and destination uniqueness) and three intrinsic motivations (i.e. self-presentation, relationship maintenance and entertainment) are proposed as antecedents. Using the data collected from 269 domestic tourists in Xiamen, we find that both extrinsic and intrinsic motivations have a positive impact on the intention. Specifically, destination uniqueness, relationship maintenance and entertainment have significant effects on online sharing intention.
\end{abstract}

\section{Introduction}

Tourism photography online sharing has become an increasingly popular phenomenon. For example, Lo et al. (2011) reveal that $89 \%$ of Hong Kong residents take photos during travel and $41 \%$ of them share their photos online. Sharing tourism photos online records the travel experience and also provides an opportunity for tourists to display and share their tourism experience to others (Lo et al, 2011). It also can be a kind of electronic word-of-mouth and thus plays a vital part in tourism destinations' promotion (Garrod, 2009).

Previous studies mainly focus on why people take photographs during their travel (Dijck, 2008). However, literature that explores why tourists share their photographs online is scant. Therefore, this study aims to explore the motivation of tourism photography online sharing to have a deeper understanding of the reasons behind this popular behavior. In our study, two extrinsic motivations (i.e. destination attractiveness and destination uniqueness) and three intrinsic motivations (i.e. self-presentation, relationship maintenance and entertainment) are proposed as antecedents and examined.

\section{Theory and hypotheses}

Self-determination theory (SDT) is an important theory of human motivation, development, and wellness (Deci and Ryan, 2008). Based on this theory, the motivational factors of tourism photography online sharing consist of both intrinsic and extrinsic motivations. In this study, we consider two extrinsic motivations and three intrinsic motivations in influencing tourism photography online sharing.

\subsection{Destination attractiveness, destination uniqueness and tourism photography online sharing}

Studies have demonstrated attractiveness and uniqueness are two main dimensions of destination aesthetics (Mackay and Fesenmaier, 1997; Kirillova et al, 2014, 2015). Attractiveness represents colorful, exciting, and diverse characteristics of destination, and uniqueness means the different and distinctive characteristics of destination through projecting an image of excitement and fun (Mackay and Fesenmaier, 1997). Tourism activities are exactly aesthetic activities, and tourists share their experience through online sharing to satisfy their needs of aesthetics. Therefore: 
Hypothesis 1: (a) Destination attractiveness and (b) destination uniqueness have a positive impact on tourism photography online sharing intention.

\subsection{Self-presentation, relationship maintenance, entertainment and tourism photography online sharing}

"Self-presentation means someone convey an impression to others which it is in his interests to convey (Goffman, 1959)." Sharing photos with others is considered as an effective means of achieving self-presentation (House et al, 2004). Similarly, sharing tourism photography online can present the true self during traveling to others, which makes others understand what you are like when traveling.

"Relationship maintenance is the act of preserving an existing relationship (Duck, 1999)." Studies find maintaining social relationships is a main motivation for media sharing and personal photographs sharing (Frohlich et al, 2002; House et al, 2004). Through posting tourism photos online, tourists easily share their experience with their relatives and friends, as well as receive comments about their photos.

More and more people satisfy their entertainment needs by sharing information and experience online (Lai and Yang, 2015; Krasnova et al, 2010). Similarly, we propose that tourists share photos for entertainment, because they experience fun, enjoyable, and a good time during this process (Rubin, 1988). Therefore:

Hypothesis 2: (a) Self-presentation, (b) relationship maintenance and (c) entertainment have a positive impact on tourism photography online sharing intention.

\section{Method}

\subsection{Sample}

This study was conducted in Xiamen, one of the most popular tourism destinations in China. Convenience sampling method was used and questionnaires were distributed to tourists in three famous scenic spots of Xiamen. A total of 300 questionnaires were distributed, and 269 valid questionnaires were acquired. In the respondent's profile, $42.70 \%$ were male; $56.51 \%$ were aged below $25 ; 74.63 \%$ came to Xiamen for the first time; $96.32 \%$ traveled with their friends, families and others; $43.87 \%$ came for the purpose of sightseeing, and $47.58 \%$ came for leisure.

\subsection{Measurement}

To guarantee the reliability and validity of questionnaires, we adopted established scales to measure variables. Back-translation procedure was performed to ensure the translation quality. All variables were measured using seven-point Likert-type scales from 1 (totally disagree) to 7 (totally degree). Specifically, the measurement of destination attractiveness and destination uniqueness are adopted from scales developed by Mackay and Fesenmaier (1997); items for measuring self-presentation and relationship maintenance are adapted from scales developed by Krasnova et al (2010); A three-item scale developed by Lee et al (2008) were used to measure the entertainment. A two-item scale developed by Bock et al (2005) was used to measure tourists' sharing intention. In addition, five variables were selected as control variables, including gender, age, travel experience to Xiamen, the degree of liking photography and the habit of uploading photos online.

\section{Results}

We conducted a series of confirmatory factor analysis to examine the validity of measurement model. The measurement model that included all six variables showed a good fit to the data $\left(\chi^{2}=519.42, \chi^{2} / \mathrm{df}=2.00, p<0.01, \mathrm{RMSEA}=0.06\right.$, TLI=0.94, CFI=0.95), and all the factor loadings were significant. Thus the discriminant and convergent validity were ensured. 


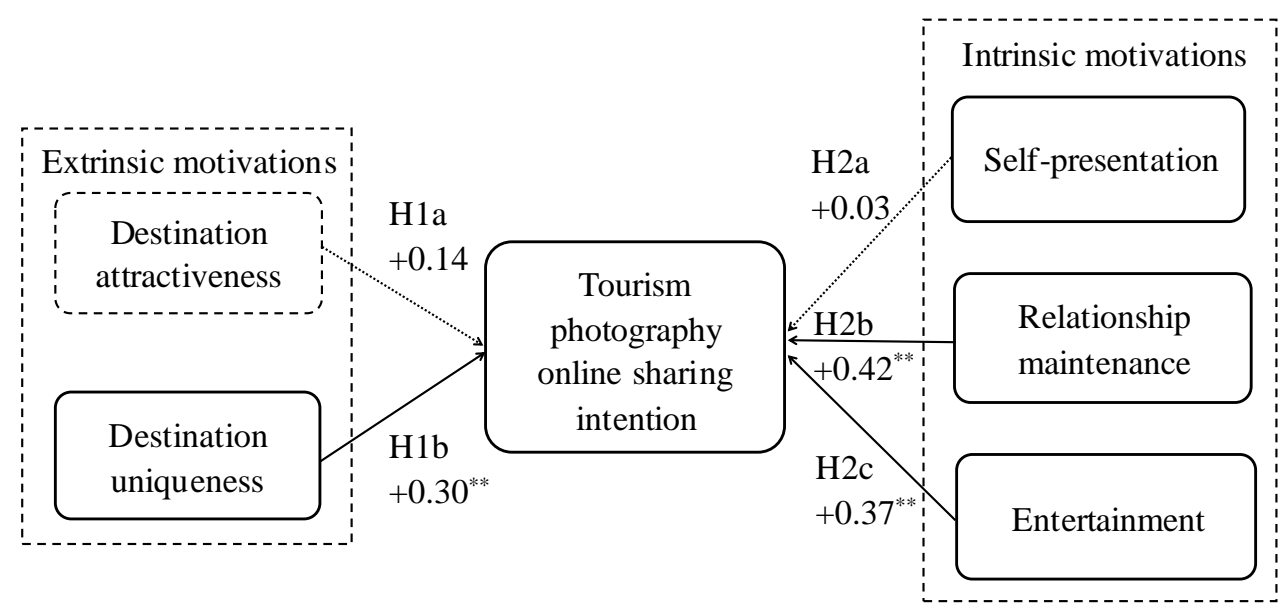

Fig. 1. Conceptual model and results

Structural equation model (SEM) was used to test the hypotheses. Firstly, we examined the relationship between extrinsic motivations and tourism photography online sharing intention $(\mathrm{H} 1 \mathrm{a}$ and $\mathrm{H} 1 \mathrm{~b})$. Model 1 showed a good fit to the data, with $\chi^{2} / \mathrm{df}=2.07(p=0.000), \mathrm{NFI}=0.93$, TLI=0.95, $\mathrm{CFI}=0.96$, RMSEA=0.06. Results showed H1a was rejected $(\beta=0.14$, N.S. $)$. While H1b $(\beta=0.30$, $p=0.006$ ) was supported. Then, we constructed Model 2, which only included three intrinsic motivations and online sharing intention. Model 2 showed a good fit to the data, with $\chi^{2} / \mathrm{df}=2.87$ $(p=0.000), \mathrm{NFI}=0.94$, TLI $=0.96, \mathrm{CFI}=0.97$, RMSEA $=0.08$. Results supported $\mathrm{H} 2 \mathrm{~b}$ and $\mathrm{H} 2 \mathrm{c}(\beta=0.42$, $p=0.000 ; \beta=0.37, p=0.000)$. But $\mathrm{H} 2$ a was rejected $(\beta=0.03, N . S$.$) .$

\section{Discussion and conclusions}

This study explores antecedents that drive tourists to share tourism photos online. Based on the aesthetic experience theory and self-determination theory, we propose two extrinsic motivations and three intrinsic motivations, and test their relationships with tourism photography online sharing intention. The results indicate that intrinsic and extrinsic motivations jointly affect online sharing intention. Compared with extrinsic motivations, intrinsic motivations have a stronger effect on the outcome.

The results show that destination uniqueness has a positive impact on tourism photography online sharing intention, but the impact of destination attractiveness is not significant. Specifically, destination uniqueness may catch tourists' attention by representing distinctive and unique characteristics of the destination, and therefore motivates tourists to share their photos online. However, destination attractiveness might be something attractive but similar, therefore failure to promote the intention.

Our study demonstrates that both relationship maintenance and entertainment have a positive and significant impact on online-photo sharing intention. Tourists want to share their tourism experience, tell friends what they are doing, and interact with others online constantly to maintain relationships, which shapes their sharing intention. In addition, tourists view tourism photography online sharing as a means of entertainment. They can obtain pleasure by communicating with others, which is another significant reason of online photo-sharing. However, self-presentation has no significant relationship with the outcome variable, indicating that tourists sharing tourism photos is not to display the best aspect of themselves and impress others.

The study has important practical implications. Since destination uniqueness is an important motivation of tourism photography online sharing, destination management and industry marketing organizations should pay attention to creating the uniqueness of destinations by highlighting the distinctiveness of destinations to facilitate tourists' photo sharing intention. What's more, this study demonstrates that relationship maintenance and entertainment are two essential intrinsic motivations of online sharing intention. Therefore, managers of tourism websites should take social interaction and entertainment into consideration in the design of the platform, e.g. increasing feedback 
functions and offering photos editing functions.

\section{Limitations and future research}

First, this study is a cross-sectional survey, and longitudinal research is needed to examine the causal relationships. Second, this study was conducted in Xiamen, China, and future research should be performed in other countries and cultural contexts to validate our findings. Finally, our study is an exploratory research which develops a framework composing several motivators on tourism photography online sharing. Future research is needed to develop this framework by integrating other potential motivations or moderators to enrich existing research.

\section{References}

[1] I. S. Lo, B. Mckercher, A. Lo, C. Cheung, and R. Law, Tourism and online photography, Tourism Management, vol. 32, pp. 725-731, 2011.

[2] B. Garrod, Understanding the relationship between tourism destination imagery and tourist photography, Journal of Travel Research, vol. 47, pp. 416-421, 2009.

[3] J. V. Dijck, Digital photography: Communication, identity, memory, Visual Communication, vol. 7, pp. 57-76, 2008.

[4] E. L. Deci, and Ryan, R. M, Self-determination theory: A macrotheory of human motivation, development, and health, Canadian Psychology, vol. 49, pp. 182-185, 2008.

[5] K. J. Mackay, and D. R. Fesenmaier, Pictorial element of destination in image formation, Annals of Tourism Research, vol. 24, pp. 537-565, 1997.

[6] K. Kirillova, X. Fu, X. Lehto, and L. P. Cai, What makes a destination beautiful? Dimensions of tourist aesthetic judgment, Tourism Management, vol. 42, pp. 282-293, 2014.

[7] K. Kirillova, and X. Lehto, Destination aesthetics and aesthetic distance in tourism experience, Journal of Travel and Tourism Marketing, vol. 32, pp. 1051-1068, 2015.

[8] E. Goffman, The presentation of self in everyday life, New York: Anchor, 1959.

[9] N. A. V. House, M. Davis, Y. Takhteyev, M. Ames, and Finn, M. The social uses of personal photography: Methods for projecting future imaging applications, University of California Berkeley Working Papers, pp. 1-12, 2004.

[10]S. Duck, Relating to others (2nd ed.), Philadelphia, PA: Open University Press, 1999.

[11]D. Frohlich, A. Kuchinsky, C. Pering, A. Don, and S. Ariss, Requirements for photoware, In Proceedings of the 2002 ACM Conference on Computer Supported Cooperative Work, New York, USA, 2002.

[12]C. Y. Lai, and H. L. Yang, Determinants of individuals' self-disclosure and instant information sharing behavior in micro-blogging, New Media and Society, vol. 17, pp. 1454-1472, 2015.

[13]H. Krasnova, S. Spiekermann, K. Koroleva, and T. Hildebrand, Online social networks: Why we disclose, Journal of Information Technology, vol. 25, pp. 109-125, 2010.

[14]R. B. Rubin, E. M. Perse, and C. A. Barbato, Conceptualization and measurement of interpersonal communication motives, Human Communication Research, vol. 14, pp. $602-628,1988$.

[15]D. H. Lee, S. Im, and C. R. Taylor, Voluntary self-disclosure of information on the Internet: A multimethod study of the motivations and consequences of disclosing information on blogs. 
Psychology and Marketing, vol. 25, pp. 692-710, 2008.

[16]G. W. Bock, R. W. Zmud, Y. G. Kim, and J. N. Lee, Behavioral intention formation in knowledge sharing: Examining the roles of extrinsic motivators, social-psychological factors, and organizational climate, Mis Quarterly, vol. 29, pp. 87-111, 2005. 